Article

\title{
Sustainable Business Models in Hybrids: A Conceptual Framework for Community Pharmacies' Business Owners
}

\author{
Caterina Cavicchi * (1) and Emidia Vagnoni \\ Department of Economics and Management, University of Ferrara, 44121 Ferrara, Italy; vgnmde@unife.it \\ * Correspondence: cvccrn@unife.it; Tel.: +390-532-455-092
}

Received: 4 August 2020; Accepted: 24 September 2020; Published: 1 October 2020

check for updates

\begin{abstract}
Community pharmacies have recently been asked to contribute to sustainable healthcare systems through active participation in an integrated model of care and by playing a major educational role for environmental conservation. Therefore, dramatic changes in their institutional context have led to increasing competition in the drugs retail sector and a shift toward a service-oriented business. These factors urge rethinking of the business model of these hybrid organizations, which combine a profit-oriented, social, and more recently addressed, environmental identity. This paper aims at discussing a sustainable business model (SBM) that could allow community pharmacies to contribute to public health through pharmacists' current role and development of that role. The effects of the COVID-19 pandemic suggest that human health should be at the center of the sustainable development agenda; the pandemic raises questions about the traditional role of community pharmacies, such as extending patient-oriented services. The SBM for community pharmacies represents an opportunity to enhance their role among the healthcare workforce, especially in a time of global pandemics. In addition, the SBM can support community pharmacies to integrate sustainability in day-to-day pharmacy practice, although it should be customized based on the contextual characteristics of the business and on differences between countries, such as health policies and regulations.
\end{abstract}

Keywords: sustainable business model; community pharmacies; pharmacy practice; public health; COVID-19

\section{Introduction}

The community pharmacies are subject to heterogeneous value logics that reflect their hybridity; indeed, they stand at the interface between the profit and not-for-profit sectors. On the one hand, community pharmacies are entrepreneurial organizations that are subject to profit maximization, but on the other hand, they dispense medication and provide counselling and other care-related services that contribute to societal welfare. Community pharmacies operate in a regulated market shaped by a country's healthcare institutions [1]; therefore, their hybridity is characterized by: (1) environmental determinism, as they are operating under the reimbursement schemes of a government's health and pharmaceutical policies; and (2) strategic choices, which are based on customers' needs [2]. As community pharmacies can enhance people's well-being, they also tend to incorporate social duties within their mission; they have recently been asked to strengthen this role in order to address the challenges posed by UN Sustainable Development Goals (SDGs) [3-5]. These heterogeneous value logics, which combine both commercial and sustainability elements, affect their business model, which comprises strategic and organizational value choices adopted in response to the institutional context [6].

Scholars have only recently started to focus on strategic orientation and organizational structures that can enhance sustainability in the context of community pharmacies. As health-related organizations, 
community pharmacies are part of the healthcare system and are expected to "optimize social, environmental, and economic outcomes" [7]. Indeed, the integration of the three performance dimensions of sustainability, also known as the triple bottom line [8], represented one of the pioneering lenses used to interpret the sustainable management of community pharmacies $[9,10]$ and their sustainable business model (SBM). An SBM focuses on Elkington's (1997) concept of the triple bottom line $[11,12]$ and "aligns interests of all stakeholder groups, and explicitly considers the environment and society as key stakeholders" [11] (p. 44). This integration between profit orientation and social and ecological goals for organizations is recommended, because the different purposes can mutually reinforce each other to create competitive advantage [13] and generate shared value [14]. To this end, profit is an outcome but also a lever to implement social and environmental sustainability [15].

In the literature, we find attempts at theoretical grounding around SBMs and business model innovation for sustainability both empirically and conceptually [11,15-19]. However, despite the growing interest of scholars in SBM research, studies on SBM innovation (and the design and implementation of SBMs) continue to be limited [20] due to a lack of consensus and consistency on business model concepts [17]. Consequently, knowledge on business model innovation for sustainability is dispersed [14]; researchers [18] urged to develop SBM research as an integrative field [21]. Moreover, to date, no studies have discussed SBM for pharmacies, which represent hybrid organizations. To this end, scholars suggested the testing of patterns characterizing SBMs and their combinations in different contexts, based on empirical evidence [18].

Although not empirically, this paper aims to address this gap by, first, discussing the ideal features of an SBM both in terms of its strategic and organizational dimensions within these hybrids in the light of the environmental turbulence affecting their activities. Indeed, the extent to which hybrids' business models differ from the business model of traditional businesses is under-investigated [22].

Second, from a theoretical point of view, the paper contributes to SBM innovation [20] by providing a conceptual framework for community pharmacies. It contends that an SBM for community pharmacies can be drawn considering the combination of outside-in and inside-out approaches [12] to business model innovation for sustainability. Thus, an SBM for community pharmacies is designed considering the relevant literature in the field and internal elements of these organizations acting as propellers to the adoption of sustainability practices. The paper allows clarification of the strategic and organizational structures that pharmacies need in order to develop an SBM and respond to institutional plurality.

Third, adopting both managerial and organizational perspectives, the paper discusses the potential of learning-action networks for the development of an SBM for community pharmacies [23]. Indeed, in managerial studies on sustainable business modelling, a systemic approach is recommended [15,19], and the mutual relation with stakeholders of the organization's value network is the lever to develop innovative and sustainable solutions beneficial to the business, society, and the ecosystem [24]. In organizational studies, this mechanism involves hybridization $[25,26]$ of the value network that is investigated in the paper.

The SBM could allow community pharmacies to contribute to public health through extending patient-oriented services, especially in the time of COVID-19 emergency. Then, this paper aims at discussing SBM for community pharmacies as an opportunity to enhance their role among the healthcare workforce, especially in a time of global pandemics. In addition, the SBM can support community pharmacies to integrate sustainability in day-to-day pharmacy practice: the framework, which is discussed in the paper should be customized based on the contextual characteristics of the business and on differences between countries, such as health policies and regulations that may affect pharmacy practice.

The paper is organized as follows: Section 2 discusses the institutional context of community pharmacies; Section 3 introduces the theoretical background on sustainable business modelling. Sections 4 and 5 discuss, respectively, the ideal strategic and organizational structures of an SBM for community pharmacies. Section 6 discusses the evolution of SBM for community pharmacies in the 
light of COVID-19 emergency. In Section 7, some theoretical contributions, practical implications, and further research are proposed.

\section{Community Pharmacies' Institutional Context}

During the past 20 years, the community pharmacies of many countries have experienced dramatic changes due to deregulation and liberalization policies, so that the distribution of drugs, which was considered their core activity, lost importance in favor of patient-centered services and the selling of healthcare-related products, which were not based on drugs [27]. For instance, in European countries, the main criticalities community pharmacies currently face are the following $[27,28]$ :

- Increase in competition on prices of over-the-counter (OTC) drugs;

- Regulations facilitating pharmacy chains and introducing new competitors such as grocery retailers in the OTC drugs market;

- Increase in competitiveness on complementary medicine;

- A shift from the dispensary role of community pharmacists (left to hospital pharmacies) to the management of professional services, introduced by countries' health policies and related cost-saving measures;

- The advent of information technology that reshaped competitiveness (e-pharmacy; electronic prescribing matched with marketing tools to tailor offerings based on customers' preferences and reduce the amount of time dedicated to dispensing activities);

- Diversification of big retailers and supermarkets into non-conventional fields.

These criticalities have pushed pharmacy business owners to focus on: improving their business models through new competitive strategies [29], increasing their professional reputation, and achieving operational efficiency to sustain competitiveness [30].

More recently, community pharmacies were also asked to strengthen their contribution to sustainable healthcare policies, which were set by the SDGs. For instance, SDG 3 stated, "ensure healthy lives and promote well-being for all at all ages" and highlighted targets such as achieving universal coverage through access to essential safe and effective medications and vaccines and the reduction of mortality rates and chronic diseases. The SDG targets place major responsibilities on the health workforce and require the professional development of the health workforce including pharmacists [3]. Given these challenges, international health institutions and associations have started to set out a sustainable development agenda for community pharmacies [4]. For example, the International Federation of Pharmacists (2017) underlined the importance of pharmacists' counseling activities for sustainability given that "as medicines experts, the pharmaceutical workforce plays a key role in improving health outcomes through responsible use of medicines and optimizing effective choice and use." Furthermore, the Pharmaceutical Group of the European Union [31] recommended a list of actions that they expected European countries to implement in order to enable community pharmacies to contribute to high-quality, inclusive, and sustainable healthcare systems. This list of actions included:

- The expansion of community pharmacies' services as an integral part of primary care;

- Improved access to innovative medicines by increasing their supply via community pharmacies;

- Incentivization of the uptake of generic drugs through community pharmacies;

- Involvement of community pharmacies in national health policies to improve vaccination coverage and risk minimization plans for other medicinal therapies.

These developments are expected to broaden the traditional expertise of community pharmacies on the dispensing of drugs and counseling to ensure the achievement of SDGs.

The environmental turbulence affecting community pharmacies' activities requires business model innovation aimed at supporting these organizations in their response to calls for more sustainable healthcare systems while maintaining competitiveness. Indeed, sustainable business modelling can 
help these organizations to respond to the heterogeneous value logics that characterize the institutional context [6].

\section{Sustainable Business Modelling: Theoretical Background}

Business model innovation helps to align a business model with environmental complexity, where the business model includes the definition of the purpose and goals of a firm and the organizational design affecting its effectiveness, efficiency, and agility [32]. A business model incorporates the ways in which a firm creates and delivers value to customers and how it is able to convert this value into profit [33,34]; so, a business model's functions consist of value creation, delivery, and capture [35]. However, the tools of traditional profit-normative business models are unable to address the complexity of sustainability issues [36].

Sustainability requires organizations to rethink how they do business [37]; therefore, orientating business model innovation toward sustainability represents a key capability for them. In the literature pertaining to SBMs, a company's value capture consists of capturing "economic value while maintaining or regenerating natural, social, and economic capital beyond its organizational boundaries" [23] (p. 6), so that a holistic view that considers both benefits and costs for stakeholders, such as society and the environment, is generated [24]. Sustainability encourages organizations to move from a firm-centric to a network-centric operational logic, as they have to deal with a plurality of actors [37]. SBMs therefore represent "business models that incorporate pro-active multi-stakeholder management, the creation of monetary and non-monetary value for a broad range of stakeholder, and hold a long-term perspective" [20] (p. 404). Organizations that adopt an SBM "increase their ability to create multiple forms of value beyond financial gains" [18] (p. 147), so that financial viability as well as SDGs can be met [18].

The literature provides studies that aim at delineating the meaning, the ideal features and the process of construction of SBMs. For instance, Stubbs and Cocklin (2008) adopted an ecological modernization perspective in order to discuss internal, cultural, and structural capabilities that are needed to adopt an SBM and achieve both firm-level and system-level sustainability [15]. Other scholars proposed value mapping as a tool that an organization can use to assess its current value proposition for its value network and identify opportunities for business model redesign and realignment of different stakeholders' interests [24,38]. Abdelkafi and Täuscher (2016) used a systemic thinking approach to explain that SBMs are built on reinforcing a feedback loop among value creation for customers, value captured by the firm, and the value to the natural environment [16]. Roome and Louche (2016) focused on the organizational transformation leading to the development of an SBM [19]. Bocken et al. (2014) proposed archetypes as mechanisms to build SBMs [11]. Evans et al. (2017) introduced a unified theoretical perspective to generate business model innovations that can lead to better economic, social, and environmental performance of organizations [17]. Lüdeke-Freund et al. (2018) [18] identified patterns of SBMs to be applied "to solve specific problems at the nexus of business and sustainability" (p. 159) while providing social, economic, or ecological value or the integrations between them.

In order to sum up the main features of SBM research, Lüdeke-Freund and Dembek (2017) argued that empirical and theoretical studies on SBMs show: "(i) an explicit sustainability orientation, integrating ecological, social and economic concerns, (ii) an extended notion of value creation, questioning traditional definitions of value and success, (iii) an extended notion of value capture in term of those for whom value is created, (iv) an explicit emphasis on the need to consider stakeholders and not just customers, and (v) an extended perspective on the wider system in which SBM is embedded" [21] (p. 1670).

When discussing SBM innovation, the literature introduces two main approaches [12]: the outside-in approach through which a firm adapts its business model to well-known archetypes in order to embed sustainability in the business' activities and processes; and the inside-out approach, which addresses the potential elements within an organization that can support its change toward sustainability. With reference to the first, Bocken et al. (2014) cited by Joyce and Paquin (2016) [11,12] 
proposed the following as archetypes for SBMs: (a) maximize material productivity and energy efficiency (do more with less resources-lean, eco-efficiency); (b) create value from waste; (c) substitute with renewables and natural processes; (d) deliver functionality rather than ownership; (e) adopt a stewardship role; (f) encourage sufficiency, such as reducing overconsumption (market for second-hand goods, eliminating superfluous or overly complex functionality from products as they increase the consumption of natural resources); (g) re-purpose the business for society and the environment in which a partial solution is represented by hybrid entities that pursue profit but a part of it is reinvested in their second non-profit business; and (h) develop scale-up solutions, such as radical change to consumption patterns through collaboration with different partners and open innovation. Scholars [18] extended the discussion on ideal features of SBMs trying to fill the gap in knowledge dispersion. The authors [18] identified patterns that can represent businesses' response to sustainability problems and classified them on the basis of the social, economic, and environmental value each business model solution brings.

With regards to the inside-out approach, this is based on the analysis of the internal elements of a firm that can act as facilitators to implement sustainable business practices; it is based on the use of planning tools, such as the Triple Layered Business Model Canvas developed by Joyce and Paquin (2016) starting from acknowledging the limits of Osterwalder and Pigneur's (2010) traditional Business Model Canvas [12,39]. This latter tool however does not take into account the social and ecological context and its links with the business when addressing sustainability [36].

In this paper, the two approaches to SBM innovation derived from the literature, the outside-in and the inside-out approaches, are combined and adapted to the specific operational features and professional expertise of community pharmacies to create an ideal SBM for community pharmacies (Figure 1).

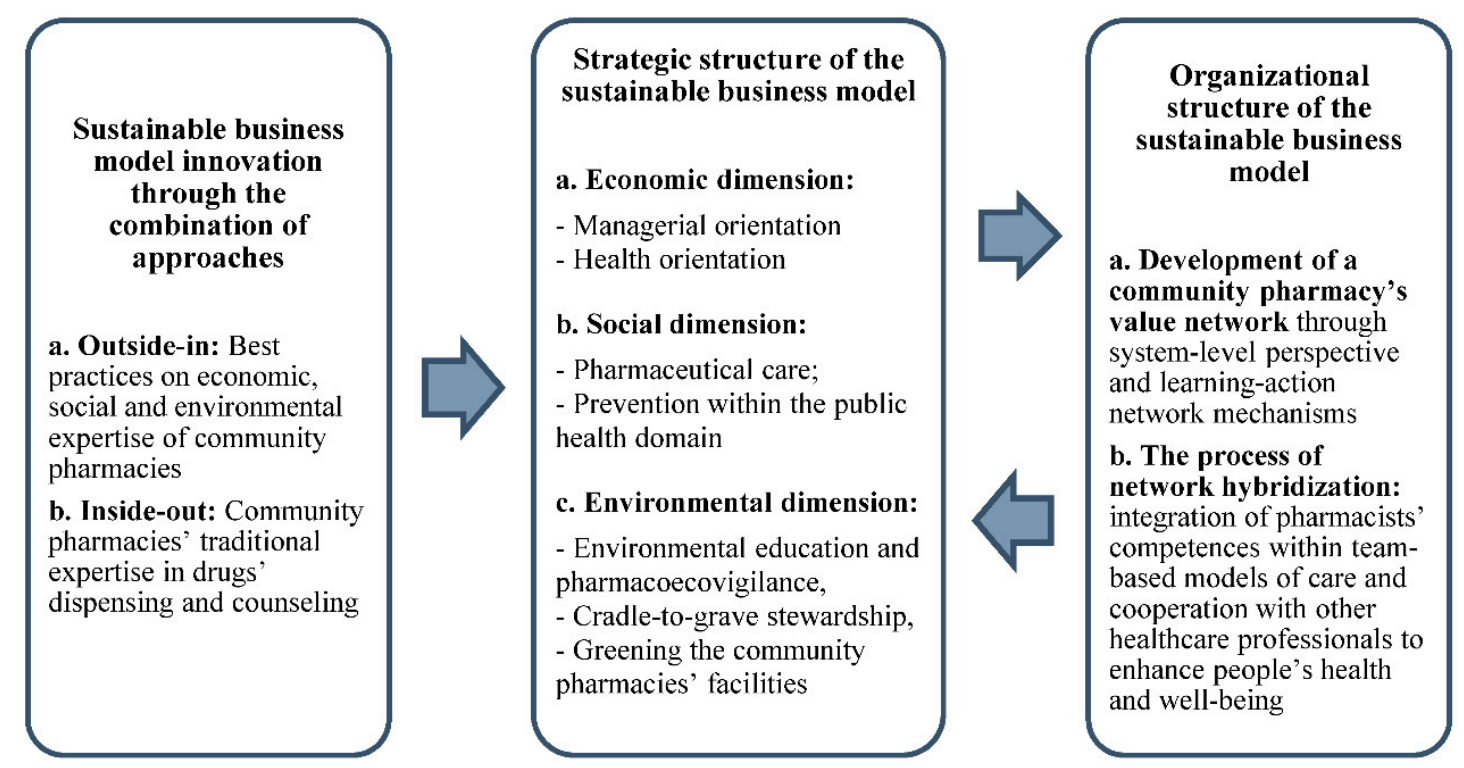

Figure 1. A sustainable business model for community pharmacies.

In the box on the left, SBM innovation through the combination of the outside-in and inside-out approaches is applied to the context of community pharmacies. On the one hand, the outside-in approach is related to best practices related to community pharmacies that have developed economic, social, and environmental expertise to respond to the challenges of the institutional environment. On the other hand, inside-out is related to competences that are already available in community pharmacy practice, which are generally related to drugs' dispensing and counseling. Sustainable business innovation drives the construction of the strategic structure of the SBM, consisting of economic, social, and environmental practices; these practices can be adopted by community pharmacies in 
order to create value for both the business and the value network; indeed, community pharmacies are hybrid organizations that have to satisfy a multitude of stakeholders' interests. An arrow pointing from sustainable business innovation to the strategic component of the SBM represents this relation. In turn, the strategic component of the SBM drives the organizational design, which is functional to the achievement of long-term goals (the two arrows between the strategic component box and the organizational structure box represent this mutual relation). The variables in the model are discussed in the next section.

\section{SBM and Community Pharmacies: Strategic Structure}

In next subsections, the strategic structure of an SBM for community pharmacies is proposed, focusing on economic, social, and environmental practices that can be adopted to allow sustainable value creation for both the pharmacy and its value network.

\subsection{Economic Dimension}

The economic dimension of the strategic structure of the business model for community pharmacies is explained in relation to managerial orientation and health orientation.

\subsubsection{Managerial Orientation}

Community pharmacies operate within a regulated environment where the health provider or insurer for retailing often defines remuneration and dispensing functions. New payment mechanisms are slowly emerging in the arena of patient-centered services as reforms extend the role of pharmacists as primary care health professionals [40]. Decreasing margins caused by increasing competitiveness [29] led to community pharmacies being perceived as entrepreneurial organizations that rely on profit generation and cost control to gain financial viability. Factors of deregulation and the emergence of new market players in the segment of drug distribution progressively required community pharmacies to develop a managerial attitude based on creativity and innovation [28] and to differentiate their offering [29]. With reference to managerial orientation, Al-Arifi (2013) described the tasks that the pharmacist, owner, and manager of a small community pharmacy should perform to enable their firm to reach optimal productivity levels. The tasks include: the selection and motivation of human resources; layout management; strategizing and marketing; management of the warehouse and inventory; and the correct use and management of information systems, such as accounting tools (collection and provision of data to the pharmacy staff), for management control of activities carried out coherently with changing regulations and markets [41]. Many studies have underlined the need for small pharmacies to use marketing mix levers adapting to the socio-demographic characteristics of the consumers to tailor offerings toward their preferences [28,42]. In addition, competences and relational skills were found to be a source of consumers' trust $[27,30]$ and can help community pharmacies to develop brand personality to compete with the new market's players [30]. Key managerial competences for pharmacists are to comprehend the strategic and operational levels of activities: the strategic level of activities includes risk taking, capacity to innovate, competitor analysis, and budgeting/financial planning; the operational level of activities includes the ability to negotiate with suppliers, cooperation with other health professionals, and staff coordination tasks [43].

\subsubsection{Health Orientation}

Community pharmacies generally represent a first reference point for people for the dispensing of drugs and counseling activities. More recently, community pharmacies were asked to extend their role beyond the dispensing of medications and counseling to contribute to societal healthcare $[44,45]$. A recent study [46] underlined that community pharmacies could become financially sustainable centers for health and personal care if they shifted from a product-oriented business model to a service-oriented business model characterized by: (a) connecting people with healthcare professionals and (b) focusing on the quality and quantity of patients' outcomes achieved. This implies the abandonment of traditional 
management approaches and the sole commercial orientation of community pharmacies in order to "(1) be focused on optimizing care, (2) use patient care business models, and (3) be conducive to patients 'receiving care' rather than purchasing products" [46] (p. 3). At the same time, the expansion of superior quality professional pharmacy services could represent a source of competitive advantage [44,47].

\subsection{Social Dimension}

The social dimension of the business model for community pharmacies has been deployed in two main areas: pharmaceutical care (PC) and disease prevention within the public health domain.

\subsubsection{PC}

The role of the pharmacist "is patient-centered care with all the cognitive functions of counseling, providing drug information and monitoring drug therapy, as well as technical aspects of pharmaceutical services, including medicines supply management" [48] (p. 4). According to this statement, pharmacists have a huge responsibility in developing a generative safety culture oriented to patients where risk management is routinized to prevent errors and mitigate their impacts (Ashcroft et al., 2005). In addition to their roles of drugs' dispenser and counselors, pharmacists can play a crucial role within the healthcare system in contexts such as PC, disease prevention, and public health delivery. PC has been defined as "the responsible dispensing of drug therapy in order to achieve defined outcomes that improve the quality of life of the patient" [49] (p. 539). Coherent with this approach, the pharmacists' role is to promote safe and effective use of medicines and identify potential and existing drug-related problems for patients through three main activities: (a) assessment of appropriateness, effectiveness, and safeness; (b) set care plans in accordance with patients and other healthcare professionals (drug therapy but also preventive activities such as the promotion of healthy lifestyles); and (c) the monitoring of compliance with/effectiveness of drug therapy, such as identification of adverse effects, abuse, and misuse of drugs, but also the assessment of patients' progress during the therapy [50]. This approach to PC requires an involvement of the pharmacist in the design, implementation, and monitoring of therapeutic plans in collaboration with other health professionals [49,51].

Ensing et al. (2019) found evidence of positive cooperation between community pharmacists and healthcare organizations in addressing patients' drug-related problems after hospital discharge [52]. PC by community pharmacies has resulted in: (a) improving patients' clinical outcomes (through promoting an improvement in patients' adherence to therapy, avoiding drug interactions, and monitoring in order to avoid or minimize adverse drug reactions, etc.); (b) reducing medical costs including physician and laboratory visits, hospitalization, and so on for the healthcare system; (c) improving the productivity of patients through decreased days of sickness; and (d) improving customers' satisfaction and loyalty with reference to pharmacists' role [53-57]. Witnessing the need for greater involvement of community pharmacists in patients' care, Franco-Trigo et al. (2017) conducted a stakeholder analysis [58]. They underlined the potential benefits pharmacists could provide in cardiovascular diseases prevention and management including: patients' education on the use of medicines, monitoring of adherence to drugs' therapy, elaboration of the patients' medication profile (or a check if it is provided by a general practitioner), empowerment of patients in the management of their diseases, promotion of healthy habits, provision of services in rural areas, and patients' referral to healthcare professionals when it is advisable. Despite the above mentioned benefits of community pharmacists playing a major role in the delivery of PC services, some barriers persist; among them the public's and doctors' misperception of the role and competences of community pharmacists, the lack of collaboration between healthcare professionals that impacts their knowledge of patients' clinical paths and their needs, the lack of an adequate remuneration system for those pharmacy services delivered under an agreement with the national healthcare system, and so on [58].

It is important to remember that PC has different features depending on the context in which it is implemented [59]; so, the modality through which it is practiced and the benefits from its adoption can change depending on the health system under examination. In fact, PC has had multiple connotations 
in different countries over time: in the Netherlands, it is based on a consolidated cooperation culture between general practitioners and pharmacists to discuss patients' pharmacotherapy; in Sweden, PC is linked to the introduction of monitoring infrastructures such as the national register of patients' dispensed drugs to set PC initiatives that are voted on to identify and solve drug-related problems; in the UK, PC comprises a major counseling and prescribing role of pharmacists; in Germany, PC is related to cognitive pharmaceutical services and some programs such as diabetes counseling are certified; while in Italy, PC is typically part of a hospital's pharmacy practice [59], and only recently have national health institutions discussed actions to extend it to community pharmacies. Therefore, translating PC into sustainable practices will depend very much on the regulatory environment in which the community pharmacy under scrutiny operates.

\subsubsection{Disease Prevention within the Public Health Domain}

From a perspective of societal well-being, pharmacies can also contribute to public health because they can provide support to a national healthcare systems' campaign on disease prevention and healthy lifestyles, providing patients with the right information on how to improve and maintain their health [60]. Opportunities to support patients to make healthy living choices, in domains such as diet and nutrition, physical activity, and a reduction in alcohol consumption and tobacco smoking, and to support people with long-term conditions have been identified [61] and represent ways in which community pharmacies can contribute to public health [62]. Examples of best practices related to pharmacies that have become healthy living and information centers were already present when Anderson (2000) reviewed health promotion in community pharmacies in the UK [63]; the author proposed an improvement in the abilities of the workforce of community pharmacies through ad hoc training to integrate health promotion with PC and provision by paymasters of an adequate refund for community pharmacies' services. Currently, the situation does not seem to have changed and the criticalities that tend to persist concern the scarce representation of pharmacists by their association within healthcare policies, a lack of strong relationships with other healthcare professionals, a lack of collaboration between pharmacists in order to establish a common strategy for the provision of PC services, a lack of involvement of patients in the design of services, and so on [64]. A stakeholder analysis conducted in Nazar and Nazar's study (2018) revealed a major need for community pharmacies to collaborate with healthcare professionals at various levels in order to become the patients' port of call for services and advice [64].

Constraints due to social context can hinder the development of a new SBM [65]. Community pharmacies could be socially sustainable if such limitations were addressed not only reconsidering pharmacists' value in health policies, but also giving them professional and managerial tools to get actively involved in the provision of pharmaceutical and public healthcare services. To this end, effective promotional campaigns on the skills and competences of pharmacists are needed to increase the perception of all relevant stakeholders (patients and healthcare professionals) of the ability of community pharmacies to provide such services; patient-centered education should be included in pharmacy curricula to prepare pharmacists in the management of their relationship with customers; in addition, a change in contractual arrangements and a higher participation in the definition of healthcare policies are needed to increase pharmacists' involvement in the delivery of such services [66].

\subsection{Environmental Dimension}

The environmental dimension of the strategic structure of the business model is discussed considering the major role business owners of community pharmacies can play in environmental education and pharmacovigilance, cradle-to-grave stewardship, and the greening of community pharmacies' facilities. 


\subsubsection{Environmental Education and Ecopharmacovigilance}

Greening the pharmacy requires embedding sustainability in its organizational system and processes through ways of changing people's behavior [67]. In particular, "green pharmacy practice in a community setting, is measured by the ability of both independent and corporate pharmacy organizations to reduce pharmaceutical waste, educate consumers on the proper disposal of medicines, and provide solutions for reducing pharmaceutical contamination" [10] (p. 363). In order to prevent the environmental impact of dispensed medicines, pharmacists can act as environmental educators [68]. In particular, they can increase the awareness of consumers of the environmental consequences of their choice to consume pharmaceuticals and personal care products and advise them about greener alternatives [68-70]. In fact, the active pharmaceutical ingredients (APIs) of unused, unwanted, and expired drugs can enter ground and water systems once disposed of and cause damage to the ecosystem; indeed, pharmaceuticals and personal care products are disposed of via industrial and household sewage and waste $[69,71]$. To scholars [71,72], the increase of APIs in the environment is exacerbated by: (a) promotions by manufacturers, such as the release of free samples to healthcare professionals, and advertising that creates prescription expectations in patients; (b) over and extra-label prescribing, therapy switches, and prescriptions to treat side effects exacerbating polypharmacy; (c) dispensing, which includes availability of free and low-cost drugs and the presence of automated dispensing machines; (d) ineffective administration of healthcare, for instance unused drugs left over in hospitals and unknown duration of therapy; (e) consumer involvement and behavior, such as purchase of excessive quantity of OTC products, stockpiling drugs for future use, and filling prescriptions with no intention to use them; and (f) non-adherence and non-compliance due to both real and perceived ineffectiveness of therapy, under-dosing of drugs, aversion to use drugs, and fear of adverse reaction. Although the effects of these substances on humans are poorly known, APIs could represent incalculable risks for the whole ecosystem in the long term and the seriousness of the risks should be taken into account [73].

Discouraging patients' misuse of drugs can also positively reduce waste with cost savings to the healthcare system and to customers' own expenditure. In this field, more integrated information systems between healthcare professionals (such as the so-called electronic medical record if shared by general practitioners and pharmacists) could enable a major monitoring of patients' consumption of medicines by pharmacists and help prevent their abuse and misuse [71,73]. Healthcare professionals can then contribute to ecopharmacovigilance through prescribing and dispensing practices that are both able to orient patients to the correct use of drugs and decrease the environmental impact of these drugs [71]. Indeed, ecopharmacovigilance "can be defined as the science and activities concerning detection, assessment, understanding and prevention of adverse effects or other problems related to the presence of pharmaceuticals in the environment, which affect both human and the other animal species" [74] (p. 963). Pharmacies can also help in reducing the environmental footprint of medicines by decreasing their inventories and counseling patients about a reasonable quantity of medication to be purchased [72].

\subsubsection{Cradle-to-Grave Stewardship}

Community pharmacies can act to green the supply chain [75] in several ways: they can choose contract distributors, which use storage, transport methods, and packaging with a low environmental impact and that have environmental certifications; they can exert pressure on the pharmaceutical industry through buying behavior in order to encourage the design and production of greener drugs; and they can provide facilities for wasted drugs take-back programs [68,70,75]. The more information (and time to absorb it) is made available to pharmacists about environmental problems, and the more conscious they become, the more they will enact green purchasing practices [76]. Greening the supply chain means to consider medicines' lifecycle, from production to correct disposal and degradation processes, and to provide good alternatives to reduce drugs' environmental footprint [77]. To implement a cradle-to-grave product stewardship starting from the pharmaceutical industry, 
which is responsible for design, development, and manufacturing, can provide, in the long term, environmental and cost-effective benefits [69].

\subsubsection{Greening Community Pharmacies' Facilities}

With reference to greening community pharmacies' facilities, the literature discusses possible business practices such as: energy saving in heating, air conditioning, water, and energy use; a choice of electronics that is labeled as energy efficient and can be part of a take-back program at the end of life; renovations based on sustainable materials; investigation of sources of indoor pollution in order to reduce emissions; collaboration with municipalities in disposal programs and supporting customers in separate disposal of waste programs $[10,68,70]$. The literature shows that customers prefer community pharmacies that engage in drugs take-back programs [78]; so, pharmacies participating in these projects can contribute to reducing the environmental impact of the pharmaceutical supply chain while increasing their customer base [79]. As scholars have underlined, pharmacists are aware of the link between the use of drugs and the persistence of active ingredients in the environment when medicines are disposed of; they recognize the importance of prevention strategies, although they see their contributions limited to supporting drugs disposal or to consultancy. Therefore, educational programs are recommended in order to help pharmacists to develop and sustain their capabilities in the field of sustainable pharmacy [73].

\section{SBM and Community Pharmacies: Organizational Structure}

The next subsections shed light on the design of the organizational structure of an SBM for a community pharmacy: the development of the community pharmacy's value network and the process of network hybridization that can help achieve the strategic goals of the firm.

\subsection{The Development of a Community Pharmacy's Value Network}

Community pharmacies are hybrid organizations characterized by both utilitarian and normative identities: their utilitarian identity refers to profit maximization through competitiveness, while their normative identity concerns the provision of care activities; therefore, business owners are engaged in balancing the tensions between the two in order to meet both financial goals and improve stakeholders' health. The peculiarities of hybrids stem from these two different institutional logics [6] leading to ambiguity in performance management and measurement, and to a major need to be accountable to diverse stakeholders [22,80]. During the past decade, the pharmacies' context has progressively redefined the traits and characteristics of pharmacies and, currently, calls for a greater contribution from pharmacies to the sustainability of the health system. For instance, in 2006, the Wiedenmayer et al. (2006) in collaboration with the International Pharmaceutical Federation, released the document "Developing pharmacy practice. A focus on patient care" in which they addressed the change in pharmacy practice over the past 40 years [48]. In the document, pharmacists were depicted as playing a number of different roles within society including the roles of caregiver, decision-maker, communicator, manager, life-long learner, educator, leader, and researcher. Indeed, pharmacy practice delves into a plurality of tasks including: the ability to manage resources, the use of information technology to provide quality services; the intermediation between drugs' prescribers and patients; an educational role for patients; the capability to use evidence-based pharmacy practice to advise the healthcare system about the effective and rational use of drugs; and the ability to take the lead within multidisciplinary healthcare teams for patients' well-being [48].

Awareness of the role that pharmacists can play within this modern frame of health and sustainable development policies is revealed in the literature that recommended a major role for pharmacists in multidisciplinary healthcare teams in order to contribute to societal healthcare needs and SDGs $[50,81]$. Pharmacists could contribute to SDGs if their role was extended to disease prevention, to wellness services, and to environmental factors (Woodard et al., 2018); in support of this, there would also be a greater preference of patients and pharmacists for healthcare delivery through community-based 
pharmacies [46]. From an organizational point of view, the literature proposed that community pharmacies should become part of networks in which their skills are shared with those of other health professionals for the provision of personalized treatments. In organizational studies, this process has been called hybridization extending beyond organizational forms [25], and it occurs in "hybrid process, practices and expertises that create and enable lateral rather than vertical transfers of information and knowledge, and that in so doing produce new forms of expertise" [26] (p. 961). In more recent studies on sustainable business modelling that combine both strategy definition and organizational design, knowledge sharing of this kind is considered to bring considerable benefits if developed at the system level, with the involvement of different social actors and therefore outside organizational barriers $[15,19]$. Scholars tend to use network theory to describe the ways in which the system approach that an organization develops through mutual relations with stakeholders can contribute to economic, social, and environmental value for both; in this way, value networks represent the locus in which to promote sustainable solutions balancing manifold interests and responsibilities $[17,24,38]$. These studies are based on the idea that value networks create social and economic good by ways of exchange of tangible and intangible value [82]. The literature has underlined that the transition toward sustainable development requires the adoption of both a firm-level and a system-level perspective on value creation, so that an SBM is constructed to provide value for the organization and the socio-economic-technical environment to which it belongs [19]; this is possible when the engagement of social actors is promoted and learning-action networks are developed in order to "create, capture and distribute value in novel ways" [19] (p. 4). In this paper, it is contended that when the managerial and organizational perspectives are combined, value networks become a lever to innovative sustainable solutions developed by community pharmacies' hybridization and the business model.

\subsection{The Process of Network Hybridization}

Hybridization for community pharmacies is expected to be characterized by the emergence of new expertise that could, from one side, benefit patients and communities as the major recipients of care and well-being services, and, from the other, guarantee healthcare system sustainability while increasing the competitive advantage of these organizations. Some studies highlighted that the network ties pharmacists create and maintain with their stakeholders, such as health providers and patients, can support them in successfully taking part in team-based care models [83,84]. For instance, Turner et al. (2018) reported that collaboration with a public health agency on the management of high-risk patients has increased the ability of pharmacists to deal with such users and support care managers with patients that had a high rate of emergency room visits [83]. Sharing information with healthcare providers on patients' adherence to drugs use and on drugs regimes, assisting them in annual wellness visits and collaborating to furnish new services within community pharmacies have increased healthcare providers' knowledge of the clinical competences of pharmacists [83]. Ties with patients and cooperation with drugs' delivery drivers were also useful to identify patients' unexpressed problems and preferences for service, and to tailor staff's competences toward these complex needs [83]. Kozminski et al. (2011) reported that healthcare professionals acknowledged the benefits of the integration of pharmacists in a medical homes project, such as medication therapy management, medication reconciliation post-hospital discharge, patient chart review and patient phone follow-up [84]. In some cases, this knowledge is already internally available and can be put at the service of new sustainable practices recalling the inside-out approach to business model innovation for sustainable development [12]. In other cases, pharmacists' competences need to be strengthened through adequate interdisciplinary education to facilitate the process of integration with other healthcare practices [40]. These networks can be considered real learning-action networks affecting the creation of community pharmacies' SBMs [23], where the sharing of information on patients and cooperation developed to provide personalized care, lead to the creation of value not only for those who will benefit from the service, but also for those who have generated it. Indeed, entering innovative working environments can enable community pharmacies to respond effectively to the 
changes in the institutional environment through satisfying patients' unmet needs. This is coherent with the mutual reinforcing cycle that is created between profit generation and social and ecological goals' achievement [13].

\section{Community Pharmacies' SBM in Time of COVID-19}

Hakovirta and Denuwara (2020) argued that the emergence of public health issues with COVID-19 "has reprioritized the sustainable development goals" within the United Nations agenda as "health is no longer only a demographic or an individual-level issue, but rather a global pandemic"; so, human health should be included as a fourth pillar of the sustainable development framework [85] (p. 3). Following this orientation, the community pharmacy SBM is put to the test to face COVID-19 emergency. As the literature pointed out, countries' response to COVID-19 pandemic "will unleash the full potential of community pharmacists and thus appears more likely to accelerate the paradigm shift from dispensing and indirect clinical focus to more direct clinical and patient centered healthcare relationship with patients/customers as well as other healthcare professionals" [86] (p. 1). In fact, social distancing and self-isolation measures will require pharmacy services to adopt new methods of service delivery [87]. New roles have thus been envisaged for community pharmacists that will sometimes be accompanied by a change in regulations to respond to COVID-19 emergency: for instance, in some countries pharmacists have been authorized to continue dispensing for patients with long-term conditions to improve patients' adherence, to compound drugs because of the shortage of medicines used in the treatment of patients with COVID-19, to extend prescriptions or pass prescriptions to other pharmacists, and deliver prescriptions to patients' homes for patients requiring controlled drugs [86,87]. In addition, their support in prevention campaigns and the provision of personal protective equipment was also recognized. As argued, during the pandemic, community pharmacists remained "at the frontline of public health by serving as direct point of access for their patients" [88] (p. 1); for instance, they provided triage services reducing the burden on healthcare facilities and helped patients by providing direct support.

A prospective major role for pharmacists is telepharmacy and home delivery services to decrease direct contact with patients and to compensate for counselling. Scholars outlined that the telepharmacy criticalities that emerged during COVID-19 pandemic could be overcome if supported by adequate government and professional bodies' interventions in terms of resources and pharmacists' education initiatives [89]; indeed, emphasis must be placed on vulnerable patients with limited digital skills and health literacy, as they need special support in the use of such services [89].

The role of community pharmacists in the management of COVID-19 pandemic is and will be, however, country specific because pharmacy legislation across the world is not homogeneous. For instance, in some countries community pharmacists do not have the right to prescribe drugs; in a pandemic situation, their role could be extended to maintaining the continuity of repeat prescriptions for older patients and people with long-term conditions [87].

The response of different countries in implementing SBM to support human health pillar will vary depending on their specific contexts. In developing countries, the SBM approach was based on the bottom of the pyramid approach; the aim of this approach was to overcome issues related to poverty and the lack of resources so that SBM had a positive impact on the local community [90]. Evidence on SBM implementation in different countries and contexts was provided in Dentchev et al.'s (2018) literature review [91]. They found papers dealing with manifold approaches to sustainable business modelling in 23 different countries. They emphasized the extent to which SBM may vary across cultural, industrial, and organizational contexts, and variation in the level of analysis, which could be individual, team, organizational, inter-organizational, and of multinational type [92]. They also emphasized the need for governmental support to foster the implementation of SBM and called for "research at the intersection of political preoccupations and the development and trajectories of SBMs across different institutional regimes to examine potential convergence, but also divergence of paths to sustainability in different countries and regions" [91] (p. 701). Culture and governmental support 
can affect the implementation of SBMs [92], which leads to variation in countries' approaches to SBM depending on the institutional context. Given the scarcity of empirical studies on such differences, further research is recommended to test the effect of countries' different institutional frameworks on SBM development, especially on the concerns of community pharmacies and their role in facing COVID-19 emergency.

\section{Discussion and Conclusions}

This conceptual paper discussed the strategic and organizational structures of an ideal SBM for community pharmacies in the light of the emergent institutional context [6]; it addressed the specificities of these hybrid organizations [22], whose competitive advantage depends on the satisfaction of multiple interests pertaining to their value network.

The paper also addressed the call of Geissdoerfer et al. (2018) for studies on business model innovation for sustainability [20]. Indeed, the paper combines best practices found from the literature and the internal knowledge assets that are already available within these organizations in order to discuss the ideal features of an SBM for community pharmacies; this new perspective comes from the combination of outside-in and inside-out approaches to SBM innovation [12]. The inside-out approach is related to competences that are already available within the community pharmacy, such as being a reference point for communities for dispensing drugs and counseling activities [48], while the outside-in approach is related to best practices found in the literature on pharmacists' competences that can be developed starting from positive experience in economic, social, and environmental areas. If these competences are combined, they form the basis for strategic planning around sustainability. From the organizational design side, a systemic approach $[15,19]$ was adopted to explain the relevance of cooperation within pharmacists' value networks to make sustainable value creation, delivery and capture, effective. Indeed, the organizational structure supports the strategic structure of the SBM. To this end, pharmacists' capabilities become relevant if integration with other healthcare professionals is pursued in the name of personalized care paths for patients, through the mechanism of learning-action networks, whose role in the context of sustainable business modelling was conceptually addressed by Schaltegger et al. (2016) [23].

With respect to managerial implications, we contend that discussion of an SBM for community pharmacies could be useful to those business owners who strive to integrate sustainability into their pharmacy practice, showing that the co-existence of social, economic, and ecologic missions is possible and beneficial for both the business and its stakeholders: on the one hand, the business model that is proposed in this paper can support the development of economic, clinical, and environmental expertise for community pharmacies in order to contribute to people's health; on the other hand, its adoption can help enhance the perception of community pharmacies' professionalism and reputation, which represent sources of competitive advantage for community pharmacies.

In addition, the paper aims to raise awareness among those working in the field of health of the relevance of pharmacists in the achievement of the goals of sustainable healthcare systems, as the potential contribution of community pharmacists to SDGs is still under-evaluated in practice. The paper's recommendations are twofold. On one side, this research urges that health planning policies focus more on the concepts of value networks to ensure greater coverage of different disciplines within team-based models of care for the good of social and natural environments. Indeed, good governance based on the involvement of stakeholders, characterized by participation and involvement of stakeholders, has been discussed as a potential enabler of sustainable health [93]. On the other side, community pharmacists were at the forefront of the COVID-19 pandemic and represented the first point of contact with the healthcare system, providing patients with prompt support. This asks for health policies to contribute to a new valorization of the profession and a possible extension of the role of community pharmacists, especially in those countries in which their tasks are limited by regulations and support for the implementation of new pharmaceutical care services in response to the pandemic has been limited. 
Suggestions for new research in this field are multiple. Further studies are needed to test the SBM for community pharmacies, discussed in the paper, through empirical research. In particular, longitudinal case study research may shed light on organizations that have started the journey toward SBM and monitor the efficacy and consequences of such choices [37]. These changes may not be radical in the short term due to the presence of contextual elements acting as constraints [65]. In the community pharmacies literature, we found examples of these criticalities, for instance: pharmacists' training is inadequate to the challenges of sustainable development, the limited interdisciplinary nature of the various paths of health education, and the lack of trust and collaboration between health professionals at various levels. For these reasons, evidence of best practices that have developed in some community pharmacies' contexts can enable understanding of the extent and the modality through which these criticalities can be overcome and a long-term oriented SBM can grow. As we discussed elsewhere in the paper, existing differences in community pharmacy practice among countries and contexts do exist, so that our conceptualization of an SBM for community pharmacies should be customized, based on contingent variables affecting its construction and development. Given the limited evidence on such differences, further research is recommended to test the effect of countries' different institutional frameworks on SBM development with reference to community pharmacies and their role in facing the COVID-19 emergency.

Author Contributions: Authors contribution are the following: conceptualization, E.V. and C.C.; methodology, C.C.; validation, E.V. and C.C.; formal analysis, C.C.; investigation, C.C.; writing—original draft preparation, C.C.; writing-review and editing, C.C. and E.V.; supervision, E.V. All authors have read and agreed to the published version of the manuscript.

Funding: This research received no external funding.

Conflicts of Interest: The authors declare no conflict of interest.

\section{References}

1. Nunes, F.G.; Anderson, J.E.; Martins, L.M.; Wiig, S. The hybrid identity of micro enterprises: Contrasting the perspectives of community pharmacies' owners-managers and employees. J. Small Bus. Enterp. Dev. 2017, 24, 34-53. [CrossRef]

2. Joldersma, C.; Winter, V. Strategic management in hybrid organizations. Public Manag. Rev. 2002, 4, 83-99. [CrossRef]

3. Dugani, S.; Duke, T.; Kissoon, N. Transforming health through sustainable development. Can. Med. Assoc. J. 2016, 188, E213-E214. [CrossRef] [PubMed]

4. Rutter, V.; Chan, A.H.Y.; Tuck, C.; Bader, L.; Bates, I. Weaving the health and pharmaceutical care agenda through the themes of the commonwealth heads of government meeting (CHOGM), London 2018. J. Pharm. Policy Pract. 2018, 11, 1-4. [CrossRef]

5. Bader, L.; Duggan, C. FIP's Commitment to Action on the WHO Astana Declaration: Transforming pharmacy for better health for all. Res. Soc. Adm. Pharm. 2020, 16, 724-726. [CrossRef]

6. Laasch, O. Beyond the purely commercial business model: Organizational value logics and the heterogeneity of sustainability business models. Long Range Plan. 2018, 51, 158-183. [CrossRef]

7. Institute of Medicine. Green Healthcare Institutions: Health, Environment, and Economics: Workshop Summary; Frumkin, H., Coussens, C., Eds.; National Academies Press: Washington, DC, USA, 2007. [CrossRef]

8. Elkington, J. Cannibals with Forks: The Triple Bottom Line of 21st Century Business; Capstone: Oxford, UK, 1997.

9. Breen, L.; Garvey, O.; Mosan, G.; Matthias, O.; Sowter, J. Do we need to be Sustainable? An examination of purpose and intention behind Sustainability practice in Community Pharmacies in the National Health Service (UK). In Proceedings of the British Academy of Management Conference, Warwick, UK, 5-7 September 2017.

10. Webster, L.; Floyd, M. Green pharmacy practice. In Pharmacy Practice Today for the Pharmacy Technician; Webster, L., Ed.; Mosby: Maryland Heights, MO, USA, 2014; pp. 358-363.

11. Bocken, N.M.; Short, S.W.; Rana, P.; Evans, S. A literature and practice review to develop sustainable business model archetypes. J. Clean. Prod. 2014, 65, 42-56. [CrossRef] 
12. Joyce, A.; Paquin, R.L. The triple layered business model canvas: A tool to design more sustainable business models. J. Clean. Prod. 2016, 135, 1474-1486. [CrossRef]

13. Osterwalder, A.; Pigneur, Y. Aligning profit and purpose through business model innovation. In Responsible Management Practices for the 21st Century; Palazzo, G., Wentland, M., Eds.; Pearson Education France: Paris, France, 2011; pp. 61-75.

14. Porter, M.E.; Kramer, M.R. The big idea: Creating shared value. Harv. Bus. Rev. 2011, 89, 2-17.

15. Stubbs, W.; Cocklin, C. Conceptualizing a "sustainability business model". Organ. Environ. 2008, $21,103-127$. [CrossRef]

16. Abdelkafi, N.; Täuscher, K. Business models for sustainability from a system dynamics perspective. Organ. Environ. 2016, 29, 74-96. [CrossRef]

17. Evans, S.; Vladimirova, D.; Holgado, M.; Van Fossen, K.; Yang, M.; Silva, E.A.; Barlow, C.Y. Business model innovation for sustainability: Towards a unified perspective for creation of sustainable business models. Bus. Strategy Environ. 2017, 26, 597-608. [CrossRef]

18. Lüdeke-Freund, F.; Carroux, S.; Joyce, A.; Massa, L.; Breuer, H. The sustainable business model pattern taxonomy-45 patterns to support sustainability-oriented business model innovation. Sustain. Prod. Consum. 2018, 15, 145-162. [CrossRef]

19. Roome, N.; Louche, C. Journeying toward business models for sustainability: A conceptual model found inside the black box of organisational transformation. Organ. Environ. 2016, 29, 11-35. [CrossRef]

20. Geissdoerfer, M.; Vladimirova, D.; Evans, S. Sustainable business model innovation: A review. J. Clean. Prod. 2018, 198, 401-416. [CrossRef]

21. Lüdeke-Freund, F.; Dembek, K. Sustainable business model research and practice: Emerging field or passing fancy? J. Clean. Prod. 2017, 168, 1668-1678. [CrossRef]

22. Spieth, P.; Schneider, S.; Clauß, T.; Eichenberg, D. Value drivers of social businesses: A business model perspective. Long Range Plan. 2018, 53, 427-444. [CrossRef]

23. Schaltegger, S.; Hansen, E.G.; Lüdeke-Freund, F. Business models for sustainability: Origins, present research, and future avenues. Organ. Environ. 2016, 29, 3-10. [CrossRef]

24. Bocken, N.; Short, S.; Rana, P.; Evans, S. A value mapping tool for sustainable business modelling. Corp. Gov. 2013, 13, 482-497. [CrossRef]

25. Kurunmäki, L. A hybrid profession-The acquisition of management accounting expertise by medical professionals. Account. Organ. Soc. 2004, 29, 327-347. [CrossRef]

26. Miller, P.; Kurunmäki, L.; O'Leary, T. Accounting, hybrids and the management of risk. Account. Organ. Soc. 2008, 33, 942-967. [CrossRef]

27. Castaldo, S.; Grosso, M.; Mallarini, E.; Rindone, M. The missing path to gain customers loyalty in pharmacy retail: The role of the store in developing satisfaction and trust. Res. Soc. Adm. Pharm. 2016, 12, 699-712. [CrossRef] [PubMed]

28. Schmidt, R.A.; Pioch, E.A. Community pharmacies under pressure: Issues of deregulation and competition. Int. J. Retail Distrib. Manag. 2004, 32, 354-357. [CrossRef]

29. Gavilan, D.; Avello, M.; Abril, C. Shopper marketing: A new challenge for Spanish community pharmacies. Res. Soc. Adm. Pharm. 2014, 10, e125-e136. [CrossRef] [PubMed]

30. Perepelkin, J.; Di Zhang, D. Brand personality and customer trust in community pharmacies. Int. J. Pharm. Healthc. Mark. 2011, 5, 175-193. [CrossRef]

31. International Federation of Pharmacists. Advancing the Global Pharmaceutical Workforce towards Achieving Universal Health Coverage and the UN Sustainable Development Goals, 2017. Available online: https: //fip.org/files/fip/PharmacyEducation/2017/WHA_2017.pdf (accessed on 25 September 2020).

32. Fjeldstad, Ø.D.; Snow, C.C. Business models and organization design. Long Range Plan. 2018, 51, 32-39. [CrossRef]

33. Baden-Fuller, C.; Haefliger, S. Business models and technological innovation. Long Range Plan. 2013, 46, 419-426. [CrossRef]

34. Teece, D.J. Business models, business strategy and innovation. Long Range Plan. 2010, 43, 172-194. [CrossRef]

35. Chesbrough, H. Business model innovation: Opportunities and barriers. Long Range Plan. 2010, 43, 354-363. [CrossRef]

36. Upward, A.; Jones, P. An ontology for strongly sustainable business models: Defining an enterprise framework compatible with natural and social science. Organ. Environ. 2016, 29, 97-123. [CrossRef] 
37. Pieroni, M.P.; McAloone, T.; Pigosso, D.A. Business model innovation for circular economy and sustainability: A review of approaches. J. Clean. Prod. 2019, 215, 198-216. [CrossRef]

38. Short, S.W.; Rana, P.; Bocken, N.M.P.; Evans, S. Embedding Sustainability in Business Modelling through Multi-stakeholder Value Innovation. In Advances in Production Management Systems. Competitive Manufacturing for Innovative Products and Services; Emmanouilidis, C., Taisch, M., Kiritsis, D., Eds.; Springer: Berlin, Germany, 2012; pp. 175-183.

39. Osterwalder, A.; Pigneur, Y. Business Model Generation: A Handbook for Visionaries, Game Changers, and Challengers; John Wiley \& Sons, Inc.: Hoboken, NJ, USA, 2010.

40. Mossialos, E.; Courtin, E.; Naci, H.; Benrimoj, S.; Bouvy, M.; Farris, K.; Noyce, P.; Sketris, I. From "retailers" to health care providers: Transforming the role of community pharmacists in chronic disease management. Health Policy 2015, 119, 628-639. [CrossRef] [PubMed]

41. Al-Arifi, M.N. The managerial role of pharmacist at community pharmacy setting in Saudi Arabia. Pharmacol. Pharm. 2013, 4, 63. [CrossRef]

42. Pioch, E.A.; Schmidt, R.A. Community pharmacies as good neighbours? A comparative study of Germany and the UK. Int. J. Retail Distrib. Manag. 2004, 32, 532-544. [CrossRef]

43. Ottewill, R.; Jennings, P.L.; Magirr, P. Management competence development for professional service SMEs: The case of community pharmacy. Educ. Train. 2000, 42, 246-255. [CrossRef]

44. Moullin, J.C.; Sabater-Hernández, D.; Fernandez-Llimos, F.; Benrimoj, S.I. Defining professional pharmacy services in community pharmacy. Res. Soc. Adm. Pharm. 2013, 9, 989-995. [CrossRef]

45. Woodard, L.J.; Kahaleh, A.A.; Nash, J.D.; Truong, H.; Gogineni, H.; Barbosa-Leiker, C. Healthy People 2020: Assessment of pharmacists' priorities. Public Health 2018, 155, 69-80. [CrossRef]

46. Schommer, J.C.; Olson, A.W.; Isetts, B.J. Transforming community-based pharmacy practice through financially sustainable centers for health and personal care. J. Am. Pharm. Assoc. 2018, 59, 306-309. [CrossRef]

47. Singleton, J.A.; Nissen, L.M. Future-proofing the pharmacy profession in a hypercompetitive market. Res. Soc. Adm. Pharm. 2014, 10, 459-468. [CrossRef]

48. Wiedenmayer, K.; Summers, R.S.; Mackie, C.A.; Gous, A.G.S.; Everard, M.; Tromp, D. Developing Pharmacy Practice. A Focus on Patient Care; World Health Organization and International Pharmaceutical Federation: Hague, The Netherlands, 2006.

49. Hepler, C.D.; Strand, L.M. Opportunities and responsibilities in pharmaceutical care. Am. J. Health Syst. Pharm. 1990, 47, 533-543. [CrossRef]

50. Kehrer, J.P.; Eberhart, G.; Wing, M.; Horon, K. Pharmacy's role in a modern health continuum. Can. Pharm. J. 2013, 146, 321-324. [CrossRef] [PubMed]

51. Bernsten, C.; Björkman, I.; Caramona, M.; Crealey, G.; Frøkjær, B.; Grundberger, E.; Gustafsson, T.; Henman, M.; Herborg, H.; Hughes, C.; et al. Improving the well-being of elderly patients via community pharmacy-based provision of pharmaceutical care. Drugs Aging 2001, 18, 63-77. [CrossRef] [PubMed]

52. Ensing, H.T.; Koster, E.S.; Dubero, D.J.; van Dooren, A.A.; Bouvy, M.L. Collaboration between hospital and community pharmacists to address drug-related problems: The HomeCoMe-program. Res. Soc. Adm. Pharm. 2019, 15, 267-278. [CrossRef] [PubMed]

53. Cranor, C.W.; Bunting, B.A.; Christensen, D.B. The Asheville Project: Long-term clinical and economic outcomes of a community pharmacy diabetes care program. J. Am. Pharm. Assoc. 2003, 43, 173-184. [CrossRef] [PubMed]

54. Garrett, D.G.; Bluml, B.M. Patient self-management program for diabetes: First-year clinical, humanistic, and economic outcomes. J. Am. Pharm. Assoc. 2005, 45, 130-137. [CrossRef]

55. Munroe, W.P.; Kunz, K.; Dalmady-Israel, C.; Potter, L.; Schonfeld, W.H. Economic evaluation of pharmacist involvement in disease management in a community pharmacy setting. Clin. Ther. 1997, 19, 113-123. [CrossRef]

56. Park, J.J.; Kelly, P.; Carter, B.L.; Burgess, P.P. Comprehensive Pharmaceutical Care in the Chain Setting: Drug therapy monitoring and counseling by pharmacists contributed to improved blood pressure control in study patients. J. Am. Pharm. Assoc. 1996, 36, 443-451.

57. Wermeille, J.; Bennie, M.; Brown, I.; McKnight, J. Pharmaceutical care model for patients with type 2 diabetes: Integration of the community pharmacist into the diabetes team-A pilot study. Pharm. World Sci. 2004, 26, 18-25. [CrossRef] 
58. Franco-Trigo, L.; Hossain, L.N.; Durks, D.; Fam, D.; Inglis, S.C.; Benrimoj, S.I.; Sabater-Hernández, D. Stakeholder analysis for the development of a community pharmacy service aimed at preventing cardiovascular disease. Res. Soc. Adm. Pharm. 2017, 13, 539-552. [CrossRef]

59. van Mil, J.F.; Schulz, M. A review of pharmaceutical care in community pharmacy in Europe. Harv. Health Policy Rev. 2006, 7, 155-168.

60. Peña, C. Spanish pharmacy: Promoting sustainability through corporate social responsibility. Int. Pharm. J. 2011, 27, 1-52.

61. Vagnoni, E.; Biavati, G.R.; Felisatti, M.; Pomidori, L. Moderating healthcare costs through an assisted physical activity programme. Int. J. Health Plann. Manag. 2018, 33, 1146-1158. [CrossRef] [PubMed]

62. Root, D.; Varney, J. Pharmacy: A Way Forward for Public Health Opportunities for Action through Pharmacy for Public Health; Public Health England: London, UK, 2017; pp. 1-53.

63. Anderson, C. Health promotion in community pharmacy: The UK situation. Patient Educ. Couns. 2000, 39, 285-291. [CrossRef]

64. Nazar, H.; Nazar, Z. Community pharmacy minor ailment services in England: Pharmacy stakeholder perspectives on the factors affecting sustainability. Res. Soc. Adm. Pharm. 2018, 15, 292-302. [CrossRef]

65. Birkin, F.; Polesie, T.; Lewis, L. A new business model for sustainable development: An exploratory study using the theory of constraints in Nordic organizations. Bus. Strategy Environ. 2009, 18, 277-290. [CrossRef]

66. Saramunee, K.; Krska, J.; Mackridge, A.; Richards, J.; Suttajit, S.; Phillips-Howard, P. How to enhance public health service utilization in community pharmacy? General public and health providers' perspectives. Res. Soc. Adm. Pharm. 2014, 10, 272-284. [CrossRef]

67. Singleton, J. Greening pharmacy-Going green. Aust. J. Pharm. 2013, 94, 64-68.

68. Campbell, J. Creating an environmentally friendly pharmacy. Pharm. Pract. 2008, March/April, 41-43.

69. Kreisberg, J. Greener Pharmacy. Integr. Med. 2007, 6, 50-52.

70. Wick, J.Y. Getting to Green: How's Pharmacy Doing? Available online: https://www.pharmacytimes. com/publications/issue/2013/November2013/Getting-to-Green-Hows-Pharmacy-Doing (accessed on 25 September 2020).

71. Daughton, C.G.; Ruhoy, I.S. Green pharmacy and pharmEcovigilance: Prescribing and the planet. Expert Rev. Clin. Pharmacol. 2011, 4, 211-232. [CrossRef]

72. Daughton, C.G. Cradle-to-cradle stewardship of drugs for minimizing their environmental disposition while promoting human health. I. Rationale for and avenues toward a green pharmacy. Environ. Health Perspect. 2003, 111, 757. [CrossRef] [PubMed]

73. Götz, K.; Deffner, J. Options for a more environmentally friendly handling of pharmaceuticals. In Green and Sustainable Pharmacy; Kümmerer, K., Hempel, M., Eds.; Springer: Berlin, Germany, 2010; pp. 149-163.

74. Velo, G.; Moretti, U. Ecopharmacovigilance for Better Health. Drug Saf. 2010, 33, 963-968. [CrossRef] [PubMed]

75. Xie, Y.; Breen, L. Greening community pharmaceutical supply chain in UK: A cross boundary approach. Supply Chain Manag. 2012, 17, 40-53. [CrossRef]

76. Schaper, M. Small firms and environmental management: Predictors of green purchasing in Western Australian pharmacies. Int. Small Bus. J. 2002, 20, 235-251. [CrossRef]

77. Kümmerer, K. Sustainable from the very beginning: Rational design of molecules by life cycle engineering as an important approach for green pharmacy and green chemistry. Green Chem. 2007, 9, 899-907. [CrossRef]

78. Kotchen, M.; Kallaos, J.; Wheeler, K.; Wong, C.; Zahller, M. Pharmaceuticals in wastewater: Behavior, preferences, and willingness to pay for a disposal program. J. Environ. Manag. 2009, 90, 1476-1482. [CrossRef]

79. Thach, A.V.; Brown, C.M.; Pope, N. Consumer perceptions about a community pharmacy-based medication take back program. J. Environ. Manag. 2013, 127, 23-27. [CrossRef]

80. Mair, J.; Mayer, J.; Lutz, E. Navigating institutional plurality: Organizational governance in hybrid organizations. Organ. Stud. 2015, 36, 713-739. [CrossRef]

81. Anderson, C.; Bates, I.; Beck, D.; Brock, T.P.; Futter, B.; Mercer, H.; Rouse, M.; Wuliji, T.; Yonemura, A. The WHO UNESCO FIP pharmacy education taskforce. Hum. Resour. Health 2009, 7, 45. [CrossRef]

82. Allee, V. Value-creating networks: Organizational issues and challenges. Learn. Organ. 2009, 16, 427-442. [CrossRef] 
83. Turner, K.; Weinberger, M.; Renfro, C.; Ferreri, S.; Trygstad, T.; Trogdon, J.; Shea, C.M. The role of network ties to support implementation of a community pharmacy enhanced services network. Res. Soc. Adm. Pharm. 2018, 15, 1118-1125. [CrossRef] [PubMed]

84. Kozminski, M.; Busby, R.; McGivney, M.S.; Klatt, P.M.; Hackett, S.R.; Merenstein, J.H. Pharmacist integration into the medical home: Qualitative analysis. J. Am. Pharm. Assoc. 2011, 51, 173-183. [CrossRef] [PubMed]

85. Hakovirta, M.; Denuwara, N. How COVID-19 Redefines the Concept of Sustainability. Sustainability 2020, 12, 3727. [CrossRef]

86. Nadeem, M.F.; Soumya, S.; Mustafa, M. Is the Paradigm of Community Pharmacy Practice Expected to Shift Due to COVID-19? Available online: https://www.ncbi.nlm.nih.gov/pmc/articles/PMC7255229/ (accessed on 25 September 2020).

87. Cadogan, C.A.; Hughes, C.M. On the frontline against COVID-19: Community pharmacists' contribution during a public health crisis. Res. Soc. Adm. Pharm. 2020, in press. [CrossRef] [PubMed]

88. Bukhari, N.; Huma, R.; Bismah, N.; Zaheer-Ud-Din, B. Pharmacists at the frontline beating the COVID-19 pandemic. J. Pharm. Policy Pract. 2020, 13, 1-4. [CrossRef] [PubMed]

89. Koster, E.S.; Philbert, D.; Bouvy, M.L. Impact of the COVID-19 epidemic on the provision of pharmaceutical care in community pharmacies. Res. Soc. Adm. Pharm. 2020, in press. [CrossRef]

90. Nosratabadi, S.; Mosavi, A.; Shamshirband, S.; Zavadskas, E.K.; Rakotonirainy, A.; Chau, K.W. Sustainable business models: A review. Sustainability 2019, 11, 1663. [CrossRef]

91. Dentchev, N.; Rauter, R.; Jóhannsdóttir, L.; Snihur, Y.; Rosano, M.; Baumgartner, R.; Nyberg, T.; Tang, X.; van Hoof, B.; Jonker, J. Embracing the variety of sustainable business models: A prolific field of research and a future research agenda. J. Clean. Prod. 2018, 194, 695-703. [CrossRef]

92. Birkin, F.; Cashman, A.; Koh, S.C.L.; Liu, Z. New sustainable business models in China. Bus. Strategy Environ. 2009, 18, 64-77. [CrossRef]

93. Sobczak, E.; Bartniczak, B.; Raszkowski, A. Aging Society and the Selected Aspects of Environmental Threats: Evidence from Poland. Sustainability 2020, 12, 4648. [CrossRef]

(C) 2020 by the authors. Licensee MDPI, Basel, Switzerland. This article is an open access article distributed under the terms and conditions of the Creative Commons Attribution (CC BY) license (http://creativecommons.org/licenses/by/4.0/). 